\title{
Sopimustuotannolla edullisempaa siemenperunaa
}

\author{
Jussi Tuomisto \\ MTT Taloustutkimus, Luutnantintie 13,00410HELSINKI. jussi.tuomisto@mtt.fi
}

\begin{abstract}
Johdanto
Korkealaatuisen siemenperunan käyttö on tärkeä tekijä kun tavoitellaan hyvää perunasatoa ja halutaan tuottaa korkealaatuista ruokaperunaa. Ruokaperunantuottaja voi käyttää istutukseen joko sertifioitua siemenperunaa tai siitä lisättyä tilan omaa siementä. Perunasatojen suuruus vaikuttaa voimakkaasti ruokaperunan hintaan ja sertifioidun siemenperunan kysyntään. Tutkimuksen mukaan perunasadon kasvaessa kymmenen prosenttia perunan hinta laskee 20 prosenttia. Perunan hinnan laskiessa ruokaperunantuottaja käyttää mieluummin suhteellisesti halvempaa tilan omaa siementä istutussiemenenä kuin ostaisi sertifioitua siementä. Kun taas perunan hinta on korkealla, ruokaperunantuottajat myyvät mieluummin kaikki perunat ruokaperunaksi ja ostavat kaiken siemenen siemenperunantuottajalta. Tämän vuoksi sertifioidun siemenen kysyntä vaihtelee aiheuttaen joinakin vuosina kysytyimpien siemenperunalajikkeiden loppumisen ja toisina vuosina taas siemenperunasta on ylitarjontaa. Ylitarjontatilanteessa siemeneksi kelpaavaa perunaa joudutaan myymään ruokaperunaksi tai jäteperunaksi siemenperunantuotannon tuotantokustannuksia alemmalla hinnalla. Kysynnän ja tarjonnan ailahtelut lisäävät siemenperunan tuotantokustannuksia, mikä kostautuu ruokaperunantuottajalle korkeampana siemenperunan hintana.

Tutkimuksessa selvitettiin voidaanko siemen- ja ruokaperunantuottajien välisen sopimustuotannon avulla vähentää markkinaepävarmuutta, parantaa siemenperunakaupan osapuolten hyötyä ja samalla lisätä tehokkuutta koko perunaketjussa. Tavoitteena oli tunnistaa siemenperunamarkkinoiden keskeiset ongelmat, pohtia yhteistyön merkitystä ja laajuutta ruokaperunaketjussa sekä selvittää, miten sopimusten avulla voidaan alentaa hintariskiä ja markkinaepävarmuutta. Tarkasteltavana oli myös se, miten sopimustuotannon avulla voidaan kehittää erilaisia kannustimia, jotka aikaansaavat eri osapuolten kannalta positiivisia vaikutuksia.
\end{abstract}

\section{Aineisto ja menetelmät}

Tutkimuksen tutkimusaineisto kerättiin siemenperunan lajike-edustajilta ja siemenperunan markkinointiyhtiöiltä. Pääasiallisimmat tiedot tutkimusta varten saatiin syvähaastattelun avulla Pohjoisen Kantaperuna Oy:ltä, Raisio Yhtymän ruokaperunateollisuudelta, Siemenperunakeskukselta, Saarioisilta ja Estrellalta. Lisäksi tietoa kerättiin haastattelemalla neljää sellaista siemenperunantuottajaa, jotka ainoastaan ostavat kantasiemenen lajike-edustajalta (eli joilla ei ole tuotantosopimusta lajike-edustajan kanssa). Tilakohtaisia tietoja kerättiin 49 siemenperunatilalta eri puolilta Suomea. Syvähaastattelun avulla saatujen tietojen perusteella jaettiin siemenperunaa tuottavat tilat sopimusten perusteella viiteen luokkaan seuraavasti: 1) käteismarkkinat, 2) vertikaalinen integraatio, 3) franchising-sopimus, 4) verkostosopimus ja 5) ennakkokauppasopimus.

Ensimmäisenä kartoitettiin kunkin lajike-edustajan tai lajike-edustajan lisenssillä toimivien organisaatioiden vuosina 1997-2000 viljelyttämät siemenperunaksi sertifioidut määrät. Seuraavaksi selvitettiin, kuinka suuri osa siemeneksi kelpaavasta perunasta on jouduttu laittamaan muuhun kuin siemenkäyttöön, minkä hintainen on kunkin organisaation tarjoaman siemenperunan hinta ruokaperunantuottajalle, ja mikä on muodostunut siemenperunantuottajalle maksettavaksi keskihinnaksi ottaen huomioon, että osa siemenperunasta on jouduttu laittamaan muuhun kuin siemenperunakäyttöön. Tällä saatiin ratkaistuksi markkinoilla oleva epävarmuus eri siemenperunan tarjontaorganisaatioissa. Tämän jälkeen rakennettiin yritysbudjetteihin perustuvat tilamallit kahdelle tilakoolle, 15 ja 30 siemenperunahehtaarille ja selvitettiin miten sopimustuotanto on vaikuttanut tilojen tuloihin, kannattavuuteen ja maksuvalmiuteen, ja millaisia ovat eri osapuolten motiivit ja rajoitteet sopimustuotannon lisäämiseen ja kehittämiseen.

Siemenperunantuotannon kannattavuutta eri sopimusmalleissa tarkasteltiin nettovoittolaskelmien ja kannattavuuskertoimien avulla. Ruokaperunantuottajan hyötyä siemenperunan sopimustuotannossa ei voida pelkästään mitata siemenperunan hinnassa, koska eri siemenperunan tarjontaorganisaatiot tuottavat erikokoista siementä. Ruokaperunahehtaarin siemenkustannus on parempi ruokaperunantuottajan hyödyn mittari. Ruokaperunahehtaarin siemenkustannus voidaan laskea seuraavan kaavan mukaisesti: 
$C_{R i}=\frac{\sum_{t=1}^{m} \sum_{i=1}^{n} k_{i t} z_{i} \frac{10^{5}}{l_{i} r_{i}} w_{i t}}{m}$

Tällöin kaavassa ruokaperunahehtaarin satovuosien 1997-2000 keskimääräinen siemenkustannus $\boldsymbol{C}_{\boldsymbol{R} i}$ (euroa/ha) on laskettu kertomalla kunkin lajikkeen ja siemenkoon vaatiman istutusetäisyyden $\boldsymbol{l}_{\boldsymbol{i}}(\mathrm{cm})$ ja tarhavälin $\boldsymbol{r}_{\boldsymbol{i}}(\mathrm{cm})$ perusteella määritetty tarvittava siemenmäärä $(\mathrm{kpl} / \mathrm{ha})$ siemenpainolla $z_{i}(\mathrm{~g} / \mathrm{kpl})$ ja kertomalla tästä saatu tulo siemenen keskimääräisellä vuoden 2000 hintatasoon deflatoidulla siemenen myyntihinnalla $\boldsymbol{w}_{i t}$ (senttiä/ $\mathrm{kg}$ ) ottaen huomioon kussakin sopimusmallissa eri vuosina tuotetun siemenen osuus $\boldsymbol{k}_{i t}(\boldsymbol{k}=0, \ldots, 1$, s.e. $\boldsymbol{\Sigma} \boldsymbol{k}=1)$ eri siemenkokoluokkiin $(\boldsymbol{i}=1 \ldots n)$ ja jakamalla tästä saadut summat tarkasteltavien vuosien $\boldsymbol{t}(\boldsymbol{t}=1, \ldots, m)$ lukumäärällä $\boldsymbol{m}$.

\section{Tulokset ja tulosten tarkastelu}

Ruokaperunantuottajan mahdollisuus käyttää siemenenä muuta kuin sertifioitua siementä, aiheuttaa siemenperunantuottajalle markkinaepävarmuutta. Käteismarkkinoilla toimivat siemenperunantuottajat kohtasivat markkinaepävarmuusongelman. Esimerkiksi satovuonna 2000 noin 24 tonnin bruttosadosta vain 65,4 prosenttia siemeneksi kelpaavasta perunasta myytiin siemeneksi. Loput jouduttiin myymään ruokaperunaksi tai jäteperunaksi siemenperunantuotannon tuotantokustannuksia alhaisemmalla hinnalla.

Mitä suuremmaksi muodostuu siemenen myyntihinnan ja siemenperunan tuottajan saaman keskihinnan ero, sitä suurempi osuus siemenperunaa myydään muuhun kuin siemenkäyttöön. Siemenperunan myyntihinnan ja siemenperunantuottajan saamaan keskihinnan erotus korreloi selvästi ruokaperunan hinnan kanssa: mitä alhaisempi on ruokaperunan hinta, sitä suurempi siemenperunan myyntihinnan ja siemenperunantuottajan saaman keskihinnan erotus on ja sitä suurempi epävarmuus siemenperunamarkkinoilla vallitsee. Korrelaatiokerroin siemenperunatuottajan saaman hinnan ja ruokaperunan hinnan välillä on pienellä siemenkoolla 0,93 ja isommalla siemenkoolla 0,81 vuosien 1997-2002 ajanjaksolla.

Kuvassa 1 on esitetty ruokaperunan hinnan vaikutus siemenperunan myyntihintaan ja siemenperunantuottajan saamaan hintaan käteismarkkinoilla. Kuvassa 1 wf1 on Pienemmän siemenkoon myyntihinta, wf2 on isomman siemenkoon myyntihinta, pt1 on siemenperunatuottajan saama hinta pienemmästä siemenkoosta, pt2 on siemenperunantuottajan saama hinta isommasta siemenkoosta ja rp on ruokaperunan tilahinta, jossa katkoviiva tarkoittaa varhaisperunan hinnan muodostamaa hintashokkia. Katkoviiva siemenperunan myyntihinnan osalta tarkoittaa futuuriperusteisella hinnoittelulla tehtävää ennakkokauppaa ajankohtana, jolloin markkinoitavaa perunasatoa ei ole vielä olemassa. Iso piste on siemenperunan toimitusajankohta ruokaperunantuottajalle.

Käteismarkkinoilla ruokaperunanhinnan vaihtelu vaikuttaa voimakkaasti siemenperunantuotannon tuottovaihteluihin, epävarmuuteen ja sitä kautta kannattavuuteen. Sopimustuotannolla voitiin tuottovaihtelua vähentää. Kuvassa 2 on esitetty siemenperunantuotannon nettovoitto ja työansio eri sopimusmalleissa 15 siemenperunahehtaarin tilalla satovuosina 1997-2000.

Missään sopimusmallissa ei siemenperunantuottaja vuosien 1997-2000 välillä päässyt positiiviseen keskimääräiseen nettovoittoon. Ainoastaan satovuonna 1998, jolloin ruokaperunan hintakin oli korkeampi, käteismarkkinoilla toimivat siemenperunatuottajat saavuttivat positiivisen nettovoiton. Suurin nettovoiton vaihtelu eri satovuosien välillä oli käteismarkkinoilla. 


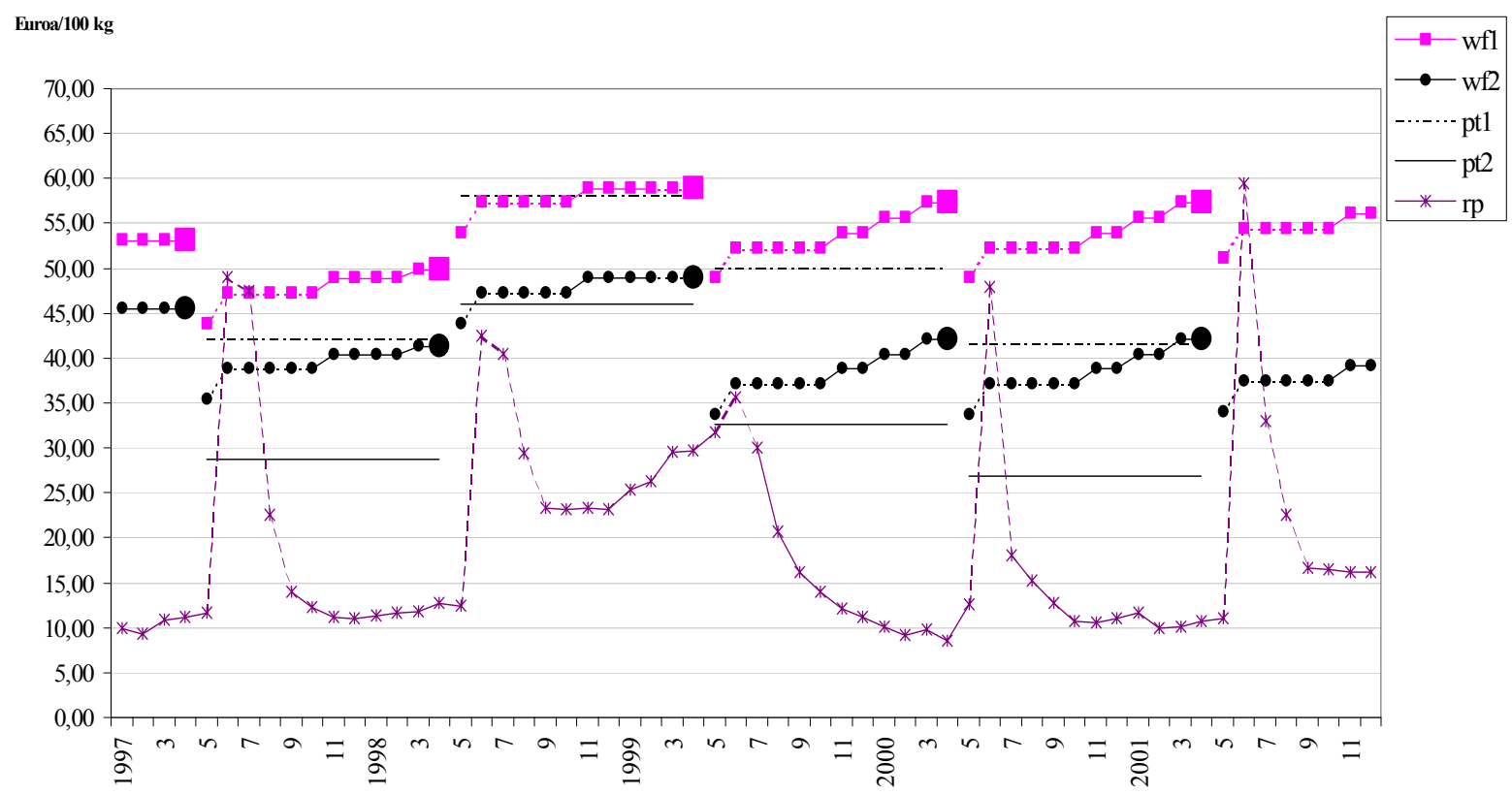

Kuva 1. Vapailla markkinoilla olevan ruokaperunan tuottajahinnan vaikutus ruokaperunantuottajan maksamaan ja siemenperunantuottajan saamaan siemenperunan hintaan.

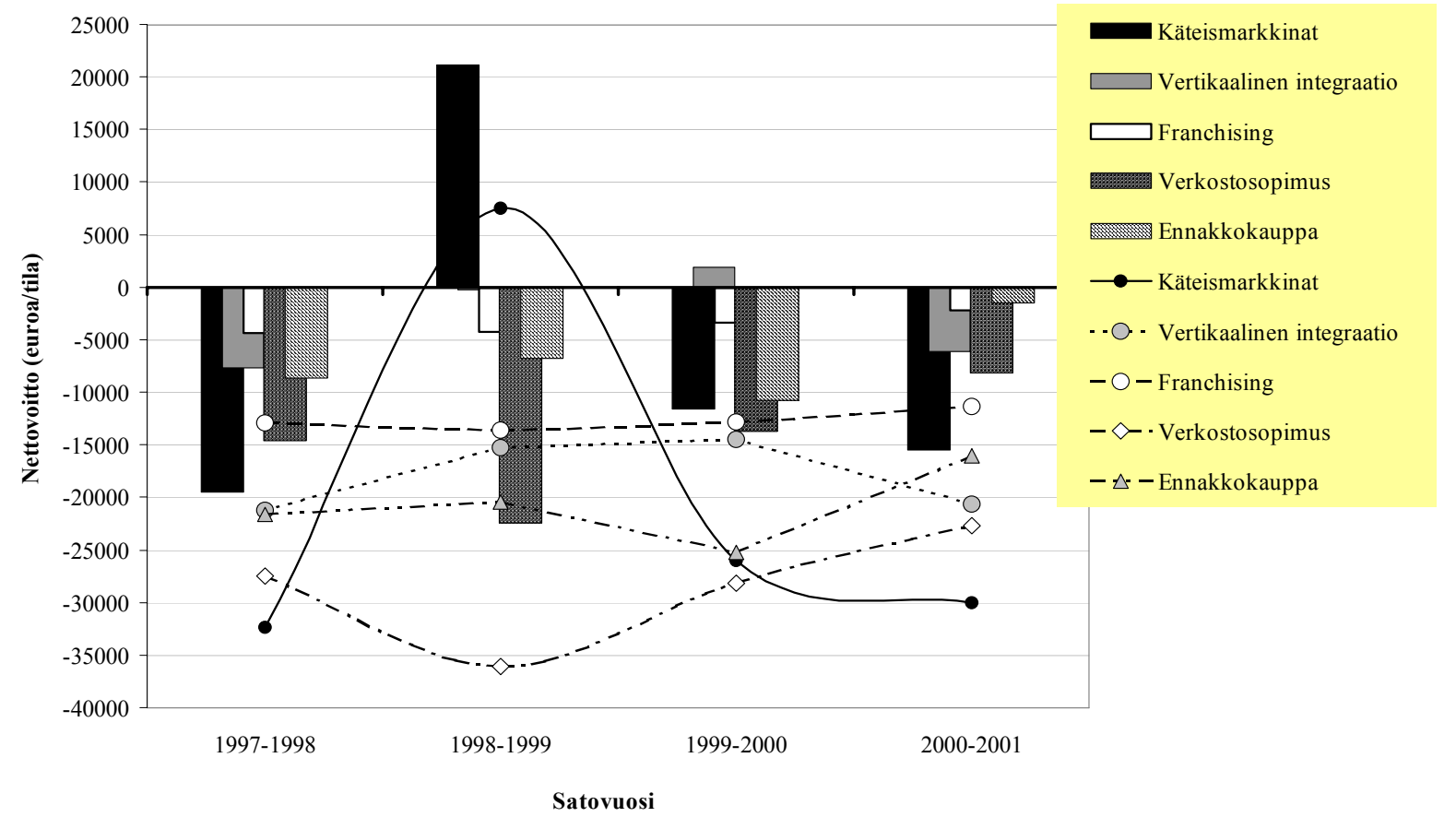

Kuva 2. Työansio ja nettovoitto (-tappio) 15 siemenperunahehtaarin tiloilla eri sopimusmalleissa satovuosina 1997-2000. Kuvassa työansio on pylväinä ja nettovoitto viivoina.

Taulukossa 1 on esitetty ruokaperunantuottajan siemenkustannuksen euromääräinen ero sekä suhdeluku eri sopimusmallien välillä verrattuna käteismarkkinoilta ostettavalla siemenellä muodostuvaan hehtaarikohtaiseen siemenkustannukseen. Mitä korkeampi on suhdeluku, sitä enemmän ruokaperunantuottaja siemenkustannuksellaan hyötyy sopimusmallista. Taulukossa on esitetty myös siemenperunantuottajien satovuosien 1997-2000 tuottama keskimääräinen nettovoitto eri sopimusmalleissa sekä eri sopimusmalleissa tuotetun nettovoiton euromääräinen ja suhteellinen ero käteismarkkinoihin 
verrattuna. Mitä korkeampi on suhdeluku, sitä enemmän siemenperunantuottaja hyötyy sopimusmallista.

Taulukko 1. Yhteenveto tuloksista satovuosilta 1997-2000.

\begin{tabular}{|c|c|c|c|c|c|c|}
\hline $\begin{array}{l}\text { Ruoka- } \\
\text { peruna- } \\
\text { hehtaarin } \\
\text { keskim. } \\
\text { siemen- } \\
\text { kustannus } \\
\text { (euroa/ha) }\end{array}$ & $\begin{array}{l}\text { Ero } \\
\text { käteis- } \\
\text { markki- } \\
\text { noihin } \\
\text { (euroa/ } \\
\text { ha) }\end{array}$ & $\begin{array}{l}\text { Suhde- } \\
\text { lukuna }\end{array}$ & $\begin{array}{l}\text { Siemen- } \\
\text { perunan- } \\
\text { tuottajien } \\
\text { keskim. } \\
\text { nettovoitto } \\
\text { (euroa/ha) }\end{array}$ & $\begin{array}{l}\text { Ero } \\
\text { käteis- } \\
\text { markki- } \\
\text { noihin } \\
\text { (euroa/ } \\
\text { ha) }\end{array}$ & $\begin{array}{l}\text { Suhde- } \\
\text { lukuna }\end{array}$ & $\begin{array}{l}\text { Siemenperun } \\
\text { antuotannon } \\
\text { kannattavuus- } \\
\text { kerroin } \\
\text { satovuosien } \\
1997-2000 \\
\text { aritmeettisena } \\
\text { keskiarvona } \\
\end{array}$ \\
\hline 1276 & 0 & 100 & -20244 & 0 & 100 & 0,31 \\
\hline 944 & -332 & 135 & -17918 & 2327 & 113 & 0,42 \\
\hline 1389 & 113 & 92 & -12693 & 7551 & 159 & 0,39 \\
\hline 642 & -634 & 199 & -28631 & -8387 & 71 & 0,03 \\
\hline 1105 & -171 & 115 & -20831 & -587 & 97 & 0,29 \\
\hline 1276 & 0 & 100 & -135 & 0 & 100 & 0,72 \\
\hline 944 & -332 & 135 & -10440 & 3143 & 130 & 0,79 \\
\hline 1389 & 113 & 92 & -7512 & 6071 & 181 & 0,78 \\
\hline 642 & -634 & 199 & -30520 & -16937 & 45 & 0,36 \\
\hline 1105 & -171 & 115 & -14395 & -812 & 94 & 0,70 \\
\hline
\end{tabular}

\section{Johtopäätökset}

Tutkimuksen mukaan siemenperunan hinnan aleneminen ei yksistään lisää siemenperunan kysyntää pitkällä aikavälillä, vaan sen lisäksi tarvitaan sopimustuotantoa vakauttamaan siemenperunan kysyntää. Kiinteähintaisessa ennakkokaupassa toimivat siemenperunantuottajat voisivat myydä siemenperunaa 13 prosenttia halvemmalla kuin ilman sopimusta - siemenperunantuotannon kannattavuuden kuitenkaan heikentymättä. Mitä yhtenäisempi tarjontaketju on, sitä vähäisempi on markkinaepävarmuus ja sitä alhaisempi myös siemenperunan hinta voi olla. Jotta siemenperunan markkinaepävarmuutta voidaan alentaa, tulisi ruokaperunantuottajan olla sopimusosapuolena mukana ketjussa. Pelkkä siemenperunantuottajan ja siemenperunan markkinointiyhtiön välinen sopimus ei alenna markkinaepävarmuutta juurikaan.

Sopimustuotantoon voidaan liittää myös siemenperunan tuotantokustannuksia korottavia tekijöitä, jotka korvataan siementuottajalle siemenperunan hinnassa. Esimerkkinä tästä on se, kun sopimusta tarjoava osapuoli haluaa siemenperunantuottajan käyttävän sellaista tuotantopanosta tai tuotantotapaa, jota siemenperunantuottaja pitäisi liian kalliina eikä kokisi itse saavansa siitä hyötyä. Sopimustuotantoon voidaan liittää myös tuotantopanosten yhteisostot, jolloin pienetkin sopimustuotantotilat pääsevät hyötymään edullisimmista tuotantopanosten hinnoista. Sopimustuotantoon liitetty kustannuskompensaatio saattaa kuitenkin aiheuttaa ns. peitellyn toiminnan ongelman: siemenperunantuottaja voi myydä siemenperunan sopimuksen vastaisesti ruokaperunaksi. Aina kun ruokaperunan hinta on korkeampi kuin siemenperunan hinta, voi siemenperunan myyminen ruokaperunaksi houkutella siemenperunantuottajaa. Sopimustuotannon avulla voidaan kontrolloida eri sopijaosapuolten tarpeet, mutta sopimusta tarjoavan osapuolen tavoitteista riippuu, mikä perunaketjun osapuoli hyötyy sopimustuotannosta eniten.

\section{Lähteet}

Tuomisto, J. 2003. Siemenperunan sopimustuotanto Suomessa. Sopimustuotanto siemenperunan markkinaepävarmuudesta aiheutuvan hyvinvointitappion alentajana. MTT, Maa- ja elintarviketalous 22, 109 s., 17 liitettä. 